Review

\title{
Cardiac Sarcoidosis: Pathophysiology, Diagnosis, and Management
}

\author{
Issa Pour-Ghaz ${ }^{1, *}$, Sharif Kayali ${ }^{2}$, Iman Abutineh ${ }^{2}$, Jay Patel ${ }^{3}$, Sherif Roman ${ }^{4}$, Mannu Nayyar ${ }^{1}$ \\ and Neeraja Yedlapati ${ }^{1}$
}

check for

updates

Citation: Pour-Ghaz, I.; Kayali, S.; Abutineh, I.; Patel, J.; Roman, S.; Nayyar, M.; Yedlapati, N. Cardiac Sarcoidosis: Pathophysiology, Diagnosis, and Management. Hearts 2021, 2, 234-250. https://doi.org/ $10.3390 /$ hearts 2020019

Academic Editor:

Matthias Thielmann

Received: 20 April 2021

Accepted: 1 May 2021

Published: 3 May 2021

Publisher's Note: MDPI stays neutral with regard to jurisdictional claims in published maps and institutional affiliations.

Copyright: (c) 2021 by the authors. Licensee MDPI, Basel, Switzerland. This article is an open access article distributed under the terms and conditions of the Creative Commons Attribution (CC BY) license (https:/ / creativecommons.org/licenses/by/ $4.0 /)$.
1 Department of Internal Medicine, Division of Cardiovascular Diseases, University of Tennessee Health Science Center, Memphis, TN 38163, USA; mnayyar@uthsc.edu (M.N.); nyedlapa@uthsc.edu (N.Y.)

2 Department of Internal Medicine, University of Tennessee Health Science Center, Memphis, TN 38163, USA; skayali@uthsc.edu (S.K.); iabutine@uthsc.edu (I.A.)

3 College of Medicine, University of Tennessee Health Science Center, Memphis, TN 38163, USA; jpatel33@uthsc.edu

4 Department of Internal Medicine, St. Joseph's University Medical Center, Paterson, NJ 07503, USA; r_romans@sjhmc.org

* Correspondence: ipourgha@uthsc.edu

\begin{abstract}
Sarcoidosis is a chronic multi-system disorder with an unknown etiology that can affect the cardiac tissue, resulting in Cardiac Sarcoidosis (CS). The majority of these CS cases are clinically silent, and when there are symptoms, the symptoms are vague and can have a lot in common with other common cardiac diseases. These symptoms can range from arrhythmias to heart failure. If CS goes undetected, it can lead to detrimental outcomes for patients. Diagnosis depends on timely utilization of imaging modalities and non-invasive testing, while in some cases, it does necessitate biopsy. Early diagnosis and treatment with immunosuppressive agents are crucial, and it is essential that follow-up testing be performed to ensure resolution and remission. This manuscript provides an in-depth review of CS and the current literature regarding CS diagnosis and treatment.
\end{abstract}

Keywords: cardiac sarcoidosis; echocardiography; positron-emission tomography; PET; sarcoidosis; implantable cardioverter-defibrillator

\section{Introduction}

Sarcoidosis is a multi-system disease of unknown etiology characterized by noncaseating granulomas in various organs. In approximately $90 \%$ of the cases, it affects the lungs and the intrathoracic lymph nodes. However, any organ can be affected, leading to its highly variable clinical presentation. When the heart is involved, cardiac sarcoidosis (CS) manifestations include benign arrhythmias, ventricular arrhythmias, high-grade blocks, sudden death, or heart failure [1]. The pathogenesis of CS involves granulomatous inflammation in the myocardium, pericardium, and endocardium in a patchy multifocal pattern. CS is the second most common cause of death in sarcoidosis patients highlighting its urgent need for recognition, since early detection of cardiac involvement and evaluating the need for glucocorticoids, antiarrhythmic drugs, pacemakers, or implantable cardioverter-defibrillator (ICD) is of great value [2]. The diagnosis of CS continues to be a challenge, given the absence of a single reliable test for the diagnosis. It is estimated that approximately 5\% have symptomatic CS in patients with systemic Sarcoidosis, and a few autopsy series have reported the prevalence of subclinical CS to be around 25\% [3]. Currently, the most commonly used methods are an electrocardiogram (ECG), echocardiogram, Holter monitors, event monitors, cardiovascular magnetic resonance imaging (CMR), and positron emission tomography with 2-deoxy-2-[fluorine-18] fluoroD-glucose Integrated with computed tomography (FDG PET/CT) [4]. This manuscript provides an in-depth review of CS, focusing on the current diagnostic modalities and treatments available. 


\subsection{Epidemiology}

CS is a global disease affecting many individuals, in most cases remaining subclinical until late stages in the disease. Estimating the disease's exact burden due to the nonuniformity in diagnostic criteria, variable presentation, and a significant amount of silent CS is cumbersome. It is estimated that sarcoidosis incidence is approximately 1-30 per 100,000, with more prevalence among the African American (AA) population, women more than men, and Northern latitudes [4]. The pattern of organ involvement and disease severity is different among various racial and ethnic groups [5]. Pulmonary sarcoidosis (PS) involvement is a cause of mortality from Sarcoidosis, affecting more women than men and more AA than Caucasians. The rate of mortality increases substantially when there is CS involvement. CS has been observed clinically in 5\% of the patients with systemic Sarcoidosis, while autopsy studies have shown cardiac involvement in $25 \%$ of the Caucasian and AA patients, and up to $80 \%$ of the Japanese patients. This underlines the high morbidity and mortality associated with CS $[2,6,7]$. There are data suggesting more predominance of CS in men than women [6]. The concern in CS is its subclinical course and under recognition. Recent studies show increased CS-related cardiomyopathy (CMP), but uncertainty remains. It is unknown whether a more widespread awareness has led to a higher recognition or this trend is representing the actual percentage previously unrecognized [7].

\subsection{Pathophysiology}

Sarcoidosis's precise mechanism has not been fully elucidated yet; however, it is widely believed to be an immunologic reaction against a novel antigen in a genetically susceptible individual [8]. These antigens are phagocytosed by macrophages and are presented to CD+ T helper cells. Secretion of interleukin-2 (IL-2) and interferon- $\gamma$ (INF- $\gamma$ ) causes activation of type-1 T-helper cells (Th1) [9]. Th1 cells play an essential role in modulating the immune response by increasing inflammatory cytokines production, including the INF- $\gamma$, transforming growth factor- $\beta$ (TGF- $\beta$ ), IL-2, and IL-12. It is this complex interplay of immunologic processes that results in non-caseating granuloma formation. The human leukocyte antigen (HLA) system encoded by the major histocompatibility (MHC) gene complex is associated with Sarcoidosis. CD4+ T-cell immunological response has been linked to HLA genes, and cardiac involvement is seen in specific subtypes, which include the DQB1*0601 and DRB1*0803 alleles [4]. In addition, single nucleotide polymorphisms in non-HLA genes such as TNF- $\alpha$ are linked to the disease. When these granulomas are located in the heart, it leads to scar and fibrosis formation. These distinct patterns can be recognized by biopsy or specific imaging patterns $[9,10]$.

\subsection{Histopathology}

CS can involve any heart layer with classic histopathology showing non-caseating granulomas [11]. Biopsy of cardiac tissue is sometimes used in diagnosing CS, but there is low sensitivity $(20-30 \%)$ due to affected myocardium being missed or having heterogeneous microscopic findings [7]. There is often multifocal involvement with progression from edema to inflammation to fibrosis to scar; the most commonly involved site is the left ventricle $(\mathrm{LV})$ in the papillary muscles and interventricular septum. It can also involve the right ventricle (RV) and atrium [2]. Early-onset CS granulomas will often show granulomas with loose macrophages with a lymphocytic predominance [12]. Worsening of CS will have more compact granulomas and decreased lymphocytes. Progression can eventually result in granulomas being replaced with dense fibrosis with lymphocytic predominance; this can also be correlated with worsening patient outcome, suggesting that decreased granulomas may be associated with worse CS due to fibrous replacement $[13,14]$. This finding also suggests that the lack of granulomas does not exclude CS. As an example, one study showed that a possibly normal histologic variant of CS could be non-specific fibrosis [15]. In some instances, a chronic M2 macrophage component (rather than lymphocytic) in a patient with CS-associated HF, suggesting that macrophages may also play a role in this fibrotic process [16]. It has also been shown that for patients whose initial CS manifestation is Ar- 
rhythmogenic Right Ventricular Cardiomyopathy (ARVC), a biopsy could show fibrofatty proliferation without a granulomatous process [17]. These examples help demonstrate that CS, histologically, can manifest in a few different ways; thus, results seen on biopsy should consider the entire clinical context for ruling in or ruling out CS [1].

\subsection{Clinical Presentation}

Sarcoidosis most commonly presents with pulmonary manifestations in $90 \%$ of patients, with cardiac involvement being rare. Those patients with localized pulmonary symptoms or more systemic symptoms will have silent cardiac Sarcoidosis 20-33\% of the time, with clinically significant CS occurring in $5-10 \%$ of cases $[7,18]$. Any part of the heart can be involved in CS, with symptoms experienced by the patient varied by disease focus and extent. The most common loci being the interventricular septum and left ventricle [4]. Symptomatic patients will experience non-specific symptoms such as fatigue, syncope, palpitations, or sudden cardiac death, often secondary to conduction anomalies, cardiomyopathy, and arrhythmias [19]. Among arrhythmias, AV nodal block is the most common, occurring in $44 \%$ of confirmed CS patients. Ventricular premature beats or ventricular tachycardia and supraventricular such as atrial fibrillation and atrial flutter, are seen in $30-32 \%$ of cases $[20,21]$. In the US, death from CS can be as high as $25 \%$, while this rate is higher in Japan, reaching up to $85 \%$ [22]. These sudden cardiac deaths are thought to be secondary to progressive conduction blockages or ventricular arrhythmias (25-65\%), or as an isolated presentation in $14 \%$ of cases [19,23]. Inflammation and fibrosis from CS can also lead to less common CS manifestations such as varying types of heart disease, including heart failure symptoms which manifest as an initial presentation in less than $20 \%$ of cases presenting with dyspnea and orthopnea, or presentation with coronary vasculitis manifesting as angina and myocardial infarction [24]. Right ventricle (RV) involvement can occur, but isolated RV involvement secondary to CS is rare and often occurs alongside LV involvement. RV systolic involvement in CS can portend a worse prognosis, and detecting CS in the RV can increase arrhythmia risk [25-27]. Due to Sarcoidosis's nature and its insidious presentation, it is essential to monitor patients with systemic Sarcoidosis for cardiac manifestations. These individuals are at an increased risk for developing heart failure in the long-term with higher mortality $[18,28]$.

\subsection{Existing Criteria for the Diagnosis of Cardiac Sarcoidosis}

Diagnosis of CS requires a combination of clinical, histologic, and imaging modalities. The main two diagnostic criteria used for CS are the Heart Rhythm Society guidelines (Table 1) [29] and the Japanese Society of Sarcoidosis guidelines (Table 2) [30,31]. There are many similarities between these two guidelines, namely the significant interplay between histologic and clinical diagnosis with imaging modalities. It can be seen that the use of endomyocardial biopsy is the most accurate method for assessment for CS. However, other secondary diagnostic tools can assist in diagnosing CS and allow for non-invasive and minimally invasive assessment for CS. 
Table 1. Heart Rhythm Society (2014). Table Adapted from Birnie et al. [29].

Histologic diagnosis

\section{Clinical diagnosis}

Cs is probable if

(a) There are histologic findings of extracardiac Sarcoidosis

AND

(b) 1 or more of the following is present:

i. Cardiomyopathy or heart block is responsive to corticosteroids + / - immunosuppressive drugs

ii. LVEF $<40 \%$ that cannot be explained

iii. SVT (spontaneous or induced) that cannot be explained

iv. Finding of Mobitz type II, second- or third-degree, heart block

v. There is patchy uptake of FDG-PET in a pattern consistent with CS

vi. LGE on CMR consistent with typical CS pattern

vii. Positive gallium uptake in a typical pattern consistent with CS

AND

(c) Other causes have been excluded

Table 2. Japanese Society of Sarcoidosis (2017). Table Adapted from Tarsaki et al. 2017 and 2019 [30].

\begin{tabular}{l} 
Histologic diagnosis \\
\hline CS is diagnosed when a biopsy (endomyocardial or surgical) shows non-caseating granulomas \\
\hline Clinical diagnosis
\end{tabular}

If an endomyocardial biopsy is not performed or is negative, a diagnosis is made clinically.

CS is diagnosed clinically by:

A. Granulomas are seen in other organs than the heart, and there is high clinical suspicion for cardiac involvement from the following

B. When there is evidence of pulmonary or ophthalmic Sarcoidosis and there are $\geq 2$ laboratory findings and clinical findings suggesting cardiac involvement ( $\geq 2$ major or $\geq 1$ major and $\geq 2$ minor criteria)

1. Major criteria

(a) High-grade AV block or fatal VA (VF and sustained VT)

(b) Ventricular septum basal thinning or abnormal ventricular wall anatomy including LV aneurysm, thinning of middle/upper ventricular septum

(c) $\quad$ LVEF $<50 \%$

(d) 67Ga citrate scintigraphy or 18F-FDG PET revealing high tracer accumulation and uptake

(e) LGE of the myocardium under MRI

2. Minor criteria
(a) ECG showing VAs including NSVT, multifocal or frequent PVCs, BBB, axis deviation or abnormal Q waves
(b) Myocardial perfusion scintigraphy showing perfusion defects
(c) Endomyocardial biopsy showing infiltration with monocytes and moderate to severe interstitial fibrosis

\section{Characteristic laboratory and imaging findings in CS}

Clinical diagnosis of Sarcoidosis supported when $\geq 2$ of the following findings are observed:

1. High serum ACE activity

2. Elevated serum lysozyme levels

3. High serum soluble IL-2 receptor levels

4. Increased tracer uptake in 67Ga citrate scintigraphy or 18 F-FDG PET

5. A high percentage of lymphocytes in BAL with a CD4/CD8 ratio of $>3.5$

6. Bilateral hilar lymphadenopathy 
Table 2. Cont.

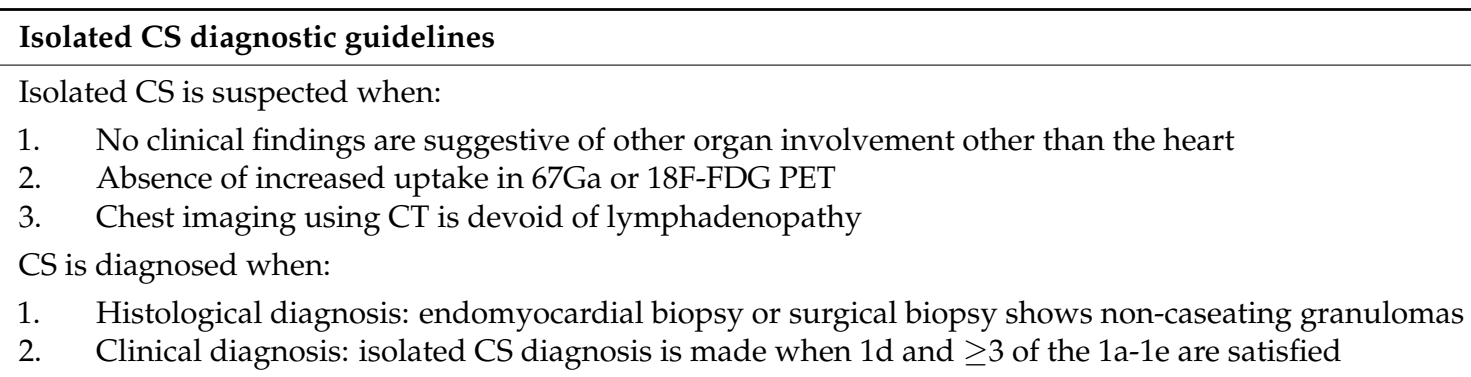

\section{Diagnostic Modalities}

\subsection{Physical Examination}

The diagnosis of Sarcoidosis can be elusive due to the heterogeneous nature of the disease. In fact, in a study of 181 patients with the biopsy-confirmed disease, CS diagnosis was made in only $15.3 \%$ of cases during the first physician visit [32]. The sub-diagnosis of CS can be further challenging, as many patients are asymptomatic early in the disease course [33]. Prognosis is poor in those with untreated CS, given the risk of complications for sudden cardiac death. For this reason, a careful physical examination is a key component for the detection of the disease.

While there is no singular manifestation that is pathognomonic for the disease, a constellation of findings can be highly suggestive of a sarcoid diagnosis. In a combined series of 1254 patients, the most frequently involved organ systems were the lungs and mediastinal lymph nodes (94\%), followed by peripheral lymph nodes (73\%) [34]. Lymphadenopathy can be detected both on physical exam or with imaging, with bilateral hilar lymphadenopathy being the most frequently described CXR finding [35]. Hepatosplenomegaly can also be appreciated [36]. Skin manifestations occur in $30 \%$ of patients, with or without systemic involvement of the disease. These findings can occur at any stage of the disease and yield a high diagnostic value on biopsy [37]. The presence of skin signs has been shown to reduce the time to diagnosis significantly [32]. While many lesions are non-specific (maculopapular, plaque-like, nodular, or ulcerative in appearance), erythema nodosum and lupus pernio are examples of classically described features of Sarcoidosis [37]. Ocular involvement also occurs in a third of patients, with the most common manifestation being uveitis [38]. While the diagnosis of Sarcoidosis generally requires biopsy confirmation, a presumptive diagnosis can be made in the presence of certain features alone. An example of this includes Lofgren syndrome, characterized by fever, erythema nodosum, bilateral hilar adenopathy, and arthritis [39]. Heerfordt syndrome involves the triad of fever, uveitis, parotitis, and cranial nerve palsy [40]. Thus, the clinical exam can be a crucial part of the identification of Sarcoidosis.

The presence of cardiac symptoms such as palpitations, orthopnea, or syncope in those with known extracardiac Sarcoidosis should raise suspicion for cardiac involvement. Signs of cardiac dysfunction are non-specific, but may include S3 or S4 gallop, displaced PMI, irregular rhythm, jugular venous distension, or cardiac murmur. In such instances, further evaluation is indicated with ECG, Echocardiography, and in some cases, PET scan, as described in the respective sections below.

\subsection{Electrocardiography}

Due to the scattered infiltrative nature of Sarcoidosis, the electrophysiologic manifestations in those with cardiac involvement are non-specific and vary widely. Most commonly, complete atrioventricular blockade (AVB) has been reported in up to $23-30 \%$ of patients [11]. This is secondary to the involvement of interventricular septum due to granulomas and subsequent scarring [11]. Importantly, AVB due to cardiac Sarcoidosis can potentially recover following corticosteroid treatment [41]; however, permanent pacing is 
indicated despite the transient reversal of AVB [42]. Ventricular tachyarrhythmias are the second most common electrophysiologic phenomena of cardiac Sarcoidosis [20] and occur due to granulomatous foci serving as an electrical reentry site [43]. Compared to AVB, ventricular tachycardia in those with cardiac Sarcoidosis confers a worse prognosis than AVB and represents an advanced disease stage [41].

QRS complex changes have been described in CS. The fragmented QRS (fQRS), defined by an additional $R$ wave $\left(R^{\prime}\right)$ or notching of the $S$ wave nadir in two contiguous leads, has been highly associated with cardiac involvement [44]. In fact, Schuller et al. showed that patients with established pulmonary Sarcoidosis and coexisting fQRS had a statistically significantly greater likelihood of cardiac involvement than those without fQRS ( $75 \%$ vs. $33.9 \%, p<0.01)$ [45]. After multivariate analysis, this study also demonstrated that the presence of either fQRS or bundle branch block was associated with an almost twentyfold greater chance of cardiac Sarcoidosis (OR 19.7, $p<0.01$ ). Therefore, while nonspecific, new right bundle branch block during follow-up in patients with non-cardiac Sarcoidosis should raise suspicion for possible cardiac Sarcoidosis [30,46]. Other nonspecific CS findings include abnormal Q waves and ST changes, which may appear in various leads as cardiac lesions due to Sarcoidosis do not correlate with coronary blood flow [47]. Overall, while the sensitivity for detecting cardiac Sarcoidosis by ECG has been low, some features may raise clinical suspicion and aid in diagnosis.

\subsection{Biomarkers}

There are no universal biomarkers for detecting cardiac Sarcoidosis, although several are under investigation for both diagnostic and prognostic value [48]. Angiotensin-converting enzyme (ACE) is one of the most frequently used biomarkers for Sarcoidosis, with elevated levels in up to $60 \%$ of affected patients. Serum ACE concentration has been thought to be a marker for disease activity, with elevated levels being associated with cardiac fibrosis on MRI [49]. However, its clinical utility has been limited by modest sensitivity and specificity [50]. Moreover, a study by Kiko et al. demonstrated that ACE levels are significantly lower $(p=0.041)$ in those with isolated cardiac sarcoid compared to those with systemic Sarcoidosis. ACE concentration did not appear to correlate with arrhythmogenicity or development of heart failure. The authors, therefore, concluded that a negative or low level of ACE should not exclude a diagnosis of CS. Similarly, IL2r does not appear to be directly correlated with disease activity in isolated CS [51].

Mankad et al. established a relationship between the concentration of C-reactive protein (CRP) and the presence of active cardiac Sarcoidosis. Notably, CRP was found to be significantly elevated in those with heart failure $(p<0.0001)$ and ventricular tachycardia $(p=0.0005)$ compared to those with sarcoid arthritis without symptomatic cardiac involvement [52]. While not specific for a cardiac sarcoid diagnosis, both CRP and the erythrocyte sedimentation rate (ESR) may prove clinically useful in monitoring response to treatment [53]. Several studies have reported a correlation between high-sensitivity cardiac troponin (hs-cTnT) and disease activity in Sarcoidosis. In a cohort of 50 patients with new-onset CS, about half were found to have elevated hs-cTnT levels normalized over a 4-week treatment course with corticosteroids [54]. This phenomenon was also reported in a case series published by Baba et al. [55]. Kiko et al. offered further insight, describing troponin I and BNP as markers of treatment response and predicting long-term outcomes. Specifically, troponin-I is associated with a greater risk of fatal arrhythmia; BNP was a predictor of heart failure. Furthermore, BNP levels were markedly more elevated in the CS group than in non-CS groups, identifying CS patients with a sensitivity of $85.4 \%$ and specificity of $68.1 \%$ [51]. Several other markers are currently under investigation with promising results, including Th1-related cytokines, myeloid-related protein 8/14 complex, U-8-OhdG, and microRNA [56,57]. 


\subsection{Echocardiography}

Echocardiography (echo) is one of the most useful tools in assessing patients with suspected cardiac involvement and is often the first imaging tool used in the vast majority of patients. Since symptoms of patients with suspected CS are generally vague, for example, syncope or palpitations, or the previous routine diagnostic tests, such as ECGs, have been non-specific, echo is usually the most appropriate next diagnostic test. However, due to its low to moderate sensitivity, a normal echo does not exclude the presence of CS. Echo for CS screening has a low specificity. Some general abnormalities seen on echo include regional wall motion abnormalities, basal septum thinning, left ventricular dilation, ventricular aneurysms, and impaired systolic or diastolic function of the right or left ventricle [58]. These wall motion abnormalities generally involve a non-coronary distribution. Even though interventricular basal wall thinning and localized aneurysms in patients with CS are usually identified as characteristic features and are highly suggestive of CS, studies have shown these features in a relatively low number of patients [59]. It is these echo changes that are utilized in the diagnostic guidelines mentioned above. A method that can increase the sensitivity for echo in the detection of CS is to combine its findings with other clues such as clinical ECG changes or Holter monitor findings. Left ventricular ejection fraction (LVEF) is also one of the strongest prognostic indicators in CS and a very useful tool in managing CS [52]. Recently, global longitudinal strain (GLS) has become a useful tool in recognizing CS patients with preserved LVEF.

\subsection{Perfusion Imaging}

Myocardial perfusion scintigraphy (MPS) is used to evaluate and detect myocardial injury at rest as well as areas of reduced myocardial perfusion reserve during rest and stress. Lesions due to cardiac Sarcoidosis on nuclear imaging classically appear as segmental reduction of radiotracer uptake in the myocardium [60]. Importantly, these perfusion defects differ from that of coronary artery disease, as the sarcoid myocardial infiltrates do not follow the territories of the coronary arteries [61]. Additionally, microvascular vasoconstriction due to sarcoid granulomas results in the phenomenon known as reverse distribution, whereby myocardial perfusion defects increase at rest as compared to stress [62]. Thallium-201, a commonly used radionuclide for MPS, ultimately cannot be used to diagnose cardiac sarcoid, particularly in the absence of symptoms [63]. Given that MPS is not specific for Sarcoidosis, the clinical setting should be considered when interpreting its results.

\subsection{Gallium-67 Scintigraphy}

Gallium-67 citrate $\left({ }^{67} \mathrm{Ga}\right)$ scintigraphy is another method of detecting cardiac Sarcoidosis. ${ }^{67} \mathrm{Ga}$ binds lactoferrin, an acute phase reactant that aggregates near focal active inflammation sites [64]. For this reason, ${ }^{67} \mathrm{Ga}$ can be used to detect areas of active sarcoid involvement, including cardiac and extracardiac sites [65]. Futamatsu et al. demonstrated a statistically significant higher risk of ventricular tachycardia in patients with cardiac ${ }^{67} \mathrm{Ga}$ uptake at time of diagnosis [66]. Importantly, ${ }^{67} \mathrm{Ga}$ used in combination with MPS has been shown to have a higher sensitivity and improved diagnostic accuracy for cardiac Sarcoidosis than either imaging modality alone [67]. In conclusion, while ${ }^{67} \mathrm{Ga}$ was formerly used more frequently, FDG-PET has largely replaced it due to its higher diagnostic sensitivity than ${ }^{67} \mathrm{Ga}[68]$.

\subsection{Endomyocardial Biopsy}

Endomyocardial biopsy (EMB) has historically been considered the gold standard for diagnosing CS [69]. The procedure is performed percutaneously, most commonly through the right internal jugular vein under fluoroscopic guidance. The complication rate in the literature varies from 1-6\% [70]. Detection of a noncaseating granuloma on histologic examination of the myocardial sample is highly specific for cardiac sarcoid [71]. However, the utility of EMB in CS has been questioned due to a high rate of false negatives 
with a sensitivity of only 20-25\% [72]. This is explained mainly by the scattered nature of disease involvement limiting the value of blind sampling [73]. In the last decade, newer diagnostic tools such as electro-anatomical mapping and imaging modalities like PET and CMR have been used to guide sampling during EMB, thereby increasing the procedure's diagnostic yield $[74,75]$. While a negative EMB does not exclude Sarcoidosis's diagnosis, the procedure can still be an appropriate tool in those with unexplained heart failure of $>3$ months duration, as described in the AHA/ACC/ESC consensus guidelines [76].

\subsection{Cardiac Magnetic Resonance Imaging}

Cardiac magnetic resonant imaging (CMR) has emerged as the diagnostic modality of choice for both ischemic and non-ischemic cardiomyopathies due to its superb ability to characterize the myocardium owing to its high spatial resolution. Regional wall motion abnormalities and myocardial thickness can be assessed with high precision on cine images, and with the utilization of late gadolinium enhancement (LGE), areas of fibrosis can be highlighted. CMR can detect edema, perfusion defects, and myocardial scar, which can be otherwise hard to characterize. CMR uses the slower washout of gadolinium in edema, inflammation, and scar to demonstrate cardiac involvement [2]. CS findings on CMR are typically divided into an acute phase and a chronic phase. Similar to echo, in the acute phase, there is the characteristic non-coronary distribution of wall motion abnormalities, increased wall thickness, and increased signal intensity on T2-weighted images to the inflammation and granulomatous lesions. In the chronic phase, also known as inactive CS, there are findings of myocardial wall thinning and aneurysmal wall formation with low signal on T2-weighted images but a high late-LGE signal intensity, which are findings suggestive of fibrosis or scar formation. These give rise to a multifocal distribution of fibrosis in the myocardium depicted pictorially in Figure 1. This distribution can be limited to the subendocardial or mid myocardial layer of the LV myocardium. However, it can also lead to more widespread involvement of the LV and RV as well, as depicted below.

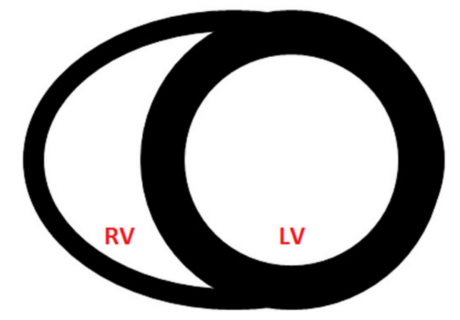

A

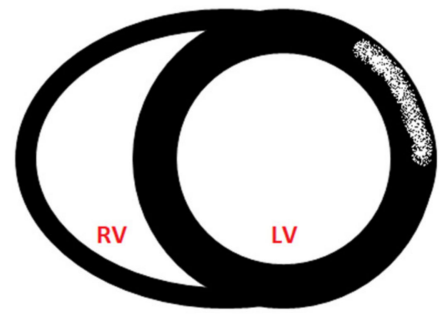

B

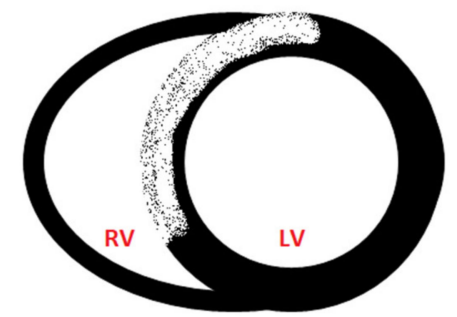

C

Figure 1. Classic patterns of LGE in Sarcoidosis. (A) normal left and right ventricular myocardium, (B) subepicardial, and $(\mathrm{C})$ transmural distribution of LGE. LV: left ventricle. RV: right ventricle.

Tissue diagnosis of CS using endomyocardial biopsy (EMB) is limited due to its inability to rule out CS because of the low sensitivity of $<25 \%$. Since CS distribution pattern is focal or patchy, the chances of inadvertently missing the involvement site is high. CMR can help with this issue by identifying the areas where tissue distribution and targeting them for sampling. This will lead to increased diagnostic accuracy. In addition, CMR can help in prognostication and in making decisions regarding therapeutic purposes [3]. It has been shown that the higher the percentage of LGE mass after treatment, especially $\geq 20 \%$, the lesser the likelihood of LV recovery [77]. It has also been shown that the presence of scar and characterization by LGE is a powerful independent risk factor for fatal events [78,79]. One important characteristic utility of CMR is its capability to characterize the tissue by mapping through T1, T2, and extracellular volume (ECV) assessment in combination with LGE to improve the diagnosis of CS. Studies have shown a higher native T1 and ECV in patients with CS, while T2 signals have been shown to be notably higher in patients with suspected CS $[80,81]$. Another useful CMR utilization is that it can be used to as- 
sess treatment response by using improvements in T1 and T2 mapping in patients after treatment [82]. Crouser and colleagues point out that LGE findings on CMR have a direct histopathological correlation with CS and the prevalence of CMR-LGE abnormalities in CS patients approaches that of CS prevalence reported in serial autopsies. The absence of LGE is a good predictor for no serious cardiac events for at least three years to follow, and the extent of LGE correlates with the future risk of adverse events [83]. Some other significant advantages of CMR are its wider availability and lesser expense [83]. CS has some characteristic distribution patterns that make more likely to occur, as shown in Figure 1. The usual distribution of CS is in the subepicardial, mid myocardial, and transmural. However, it can also rarely involve the subendocardium.

CMR has some limitations which cannot be forgotten. One major limitation of CMR is the contraindication of gadolinium use in patients with renal impairment. One significant limitation is that other cardiac diseases can show similar LGE findings on CMR [84]. Thus, when applying CMR, the clinician should be cognizant of these limitations.

\subsection{F-18 FDG PET/CT}

Fluorodeoxyglucose (FDG) Positron Emission Tomography (PET)/Computer Tomography $(\mathrm{CT})$ imaging is among the most sensitive and specific imaging modalities for the diagnosis of CS. It utilizes FDG, a radiolabeled glucose analog, to differentiate between normal and active inflammatory lesions. Active inflammatory cells have a higher metabolic activity and a higher uptake of FDG, leading to higher signal intensity. PET portion is performed by utilizing a low-dose CT for anatomically colocalizing the areas of FDG uptake. This is opposite to what CMR does; while CMR detects scar tissue, FDG-PET/CT recognizes myocardial inflammation. Since this technique relies on the increased uptake of the inflammatory cells, the physiologic FDG uptake must be minimized as much as possible. There are various protocols for such suppression which utilize different timing of fasting and diets before testing. In addition, other causes that can affect uptake also need to be ruled out. For example, coronary artery disease could cause hibernation of myocardium or myocarditis, which could increase uptake and should therefore be ruled out [85].

Since FDG-PET imaging findings depend on the disease stage, the findings can range from those of pure inflammation, which would be the case if there is only FDG uptake to only perfusion defect, which would be the case when there is a terminal scar or a treated case of CS. If there are findings of focal or focal on diffuse FDG uptake and an area of perfusion defect in the same segments, it would be strong evidence suggesting an active area of CS. These findings should all be considered in the clinical context and with findings from other modalities [85]. The images must be assessed in terms of location, extent, and severity of the perfusion defect and the extent of FDG uptake's abnormality. The main categories for grading FDG uptake qualitatively are absent, focal, diffuse, and focal on diffuse. The extent of FDG uptake can also be visually quantified, mainly when divided into small, medium, large, and very large categories. The severity of the perfusion defects is qualitatively assessed by classifying them into mild, moderate, severe, or absent based on the standard 17 segments [86]. It should be noted that isolated uptake in specific locations is likely to be artifactual and should not be considered. Quantitative FDG uptake is expressed in standard uptake values (SUV) which is measured as mean, max, and total for the myocardium, as a cardiac to blood pool ratio, and as a total cardiac metabolic activity. Youssef et al. showed that the pooled sensitivity and specificity of FDG-PET/CT can reach up to $89 \%$ and $78 \%$, respectively [87]. It has also been shown that FDP-PET is able to predict adverse outcomes and provide prognostic information, which can be very vital in clinical decision making regarding therapeutic options. Ventricular arrhythmia (VA) and the risk of death increase by four-fold in individuals with increased FDG uptake [88], and these individuals have worse cardiovascular outcomes and events [89,90]. In treated patients who underwent FDG-PET at follow up, there was an improvement in these metrics and for an average drop of $10 \mathrm{~g} / \mathrm{mL}$ in SUV maximum, there was a correlated increase in LVEF of $7.9 \%$ in steroid-treated patients [91,92]. Considering these significant advantages of being quantita- 
tively and reproducible, FDP-PET can be a very useful tool to assess response to therapy, as well as diagnosis of CS. Undeniably, FDG-PET/CT has its own limitations, including the high cost, limited availability, lower spatial and temporal resolution compared to CMR, exposure to ionizing radiation, and a complicated dietary regimen before the test [93]. Therefore, careful consideration should be given when ordering this test, and in-depth consideration of limitations for patients are required, especially in younger patients.

\subsection{CMR and FDG-PET}

A new field of advanced cardiac imaging evolving is hybrid imaging of CS by combining PET and magnetic resonance imaging (MRI) into a single device, enabling utilization of two of the most advanced modalities for CS imaging. It has been shown that such imaging modality has superior sensitivity to MRI or PET [94], and using this technique, patients were able to be re-classified into a higher or lower likelihood grouped for CS [95]. As can be expected, it has been shown that if disease-related changes are seen on both FDG-PET and CMR, there was a higher rate of adverse cardiac events. High cost, limited availability, and scarcity of validation studies are limiting factors for more widespread utilization of this modality [96]. One substantial advantage of this hybrid imaging is the substantially lower radiation exposure, which can be particularly important and beneficial in younger patients, especially since most individuals need follow-up exams [97]. Perhaps, in the near future, with more robust clinical data, hybrid imaging will be applied more.

\section{Treatment}

\subsection{Immunosuppression}

The goal of immunosuppressive therapy in cardiac Sarcoidosis is to reduce the burden of inflammation and prevent irreversible myocardial remodeling, thereby slowing disease progression [98]. Populations that should be considered for immediate initiation of immunosuppressive therapy include those with evidence of myocardial inflammation associated with ventricular arrhythmia, heart block, or left ventricular dysfunction (Class IIa recommendation) $[7,29]$. Some experts recommend early initiation of immunosuppressive treatment, regardless of whether the above criteria are met [33,99]. Corticosteroids have long been considered the mainstay for treatment in CS, but the optimal treatment regimen has yet to be formalized in the absence of randomized clinical trials [100]. In general, prednisone is usually initiated at 30-40 mg daily for $4-8$ weeks. If treatment response is identified at follow-up evaluation, prednisone is tapered by $5-10 \mathrm{mg}$ every $2-4$ weeks until a 5-15 mg maintenance dose is achieved. The maintenance dose is continued for an additional 9-12 months prior to discontinuation. Patients should continue to be monitored every $2-3$ months for an additional 3 years to monitor for disease relapse $[7,101,102]$. Risks associated with long-term corticosteroid use include weight gain, hypertension, hyperglycemia, reduced bone mineral density, predisposition for infection, insomnia, and adrenal insufficiency, to name a few [3]. However, numerous trials have demonstrated favorable outcomes in those treated with corticosteroids, namely LVEF and the arrhythmogenicity associated with active granulomatous disease, especially when treatment is initiated early in the disease course [3]. In a systematic review of 10 studies evaluating response to corticosteroid use in CS, Sadek et al. demonstrated both maintenances of LV function in those with normal LVEF at the time of diagnosis and LV improvement function in those with mild to moderate LV dysfunction (LVEF > 35\%). However, no improvement was seen in patients with severe LV dysfunction [101]. Additionally, Yazaki et al. showed improved 5-year survival in CS patients treated with corticosteroids compared to those who were untreated (75\% vs. 10\% 5-year survival). CS patients treated with steroids with LVEF $>50 \%$ had a significantly greater survival rate compared to those with LVEF $<50 \%$ $(p<0.001)$, again highlighting the importance of early diagnosis and initiation of treatment in those with CS [102].

Methotrexate is used as second-line therapy for those who either do not respond to or have contraindications for the use of corticosteroids [7]. The recommended dose is 
5 to $20 \mathrm{mg}$ weekly. Clinicians should monitor patients for hepatotoxicity, bone marrow suppression, and renal dysfunction every 1-3 months [3]. While studies are limited mainly to small observational cohorts, a multicenter open-label, randomized control noninferiority trial (CHASM CS-RCT) is currently underway to investigate outcomes in patients treated with low-dose prednisone combined with methotrexate compared to standard dose prednisone alone [100]. Other steroid-sparing agents include mycophenolate mofetil, cyclophosphamide, azathioprine, and leflunomide, although these therapies have not been studied extensively in isolated cardiac Sarcoidosis. Figure 2 depicts the treatments used for CS in a stepwise fashion.

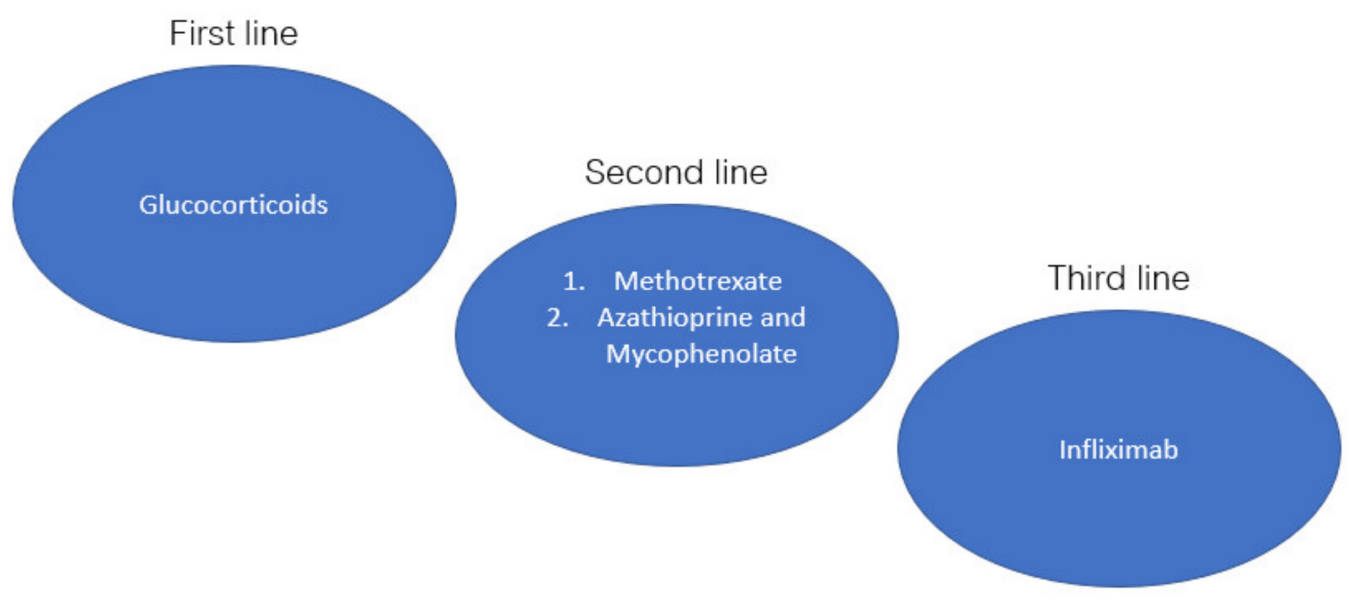

Figure 2. Cardiac Sarcoidosis stepwise approach to therapy.

Small studies utilizing Infliximab for the treatment of refractory cardiac Sarcoidosis have shown promising results. Previously, TNF alpha inhibitors were avoided in those with cardiac dysfunction due to a 2001 FDA safety alert warning of an increased incidence of mortality and hospitalization in patients with moderate to severe, non-inflammatory heart failure. However, in a case series of 36 patients with refractory CS treated with Inflix$\mathrm{imab}$, the authors demonstrated a significant reduction in prednisone requirements and improvement in arrhythmia control without evidence of worsening cardiac function [103]. While Infliximab appears to be effective in severe, refractory cases of cardiac Sarcoidosis, complications, including the infection rate, are still under investigation [104].

\subsection{Ventricular Arrhythmias}

Patients with CS are at increased risk for ventricular arrhythmias, with an incidence of approximately $15 \%$ leading to ICD therapy [105]. The primary mechanism responsible for VA in patients with CS is reentry due to sarcoid granulomatous scar formation [106]. However, evidence exists for active inflammation in those with CS as a trigger for monomorphic VT storms [107]. The use of corticosteroids for the management of VA in CS has mixed results [101]. Yodogawa et al. demonstrated a statistically significant $35 \%$ reduction in non-sustained VT in patients treated with corticosteroids $(p=0.039)$ [108]. Patients in this study notably had a LVEF $\geq 35 \%$; thus, corticosteroids may be more effective in patients with VA during earlier forms of CS than advanced stages.

In contrast, Segawa et al. reported possible reactive inflammation following corticosteroid treatment which may have increased VT frequency [109]. Regarding antiarrhythmic drugs (AADs), class I agents are contraindicated given the presence of scarring and structural heart disease in CS [110]. Typically, class III AADs are used, such as amiodarone; however, pulmonary toxicity risk should be considered, particularly in patients with advanced pulmonary Sarcoidosis [111]. In those with VT/VF storm, therapy with a combination of AADs and immunosuppression when active inflammation is suspected [29]. Overall, HRS expert consensus recommends as a class IIa indication that patients with 
CS and VA undergo FDG-PET assessment for active inflammation with subsequent use of immunosuppression if inflammation is present. Antiarrhythmics can be used in those refractory to immunosuppressive therapy; catheter ablation is considered when immunosuppression and antiarrhythmic therapy have failed [29].

\subsection{Risk Stratification for SCD and ICD Implantation}

One of the significant factors in the successful treatment of CS is utilizing and applying ICD in at-risk patients and promptly diagnosing these cases. Based on the American Heart Association/American College of Cardiology/Heart Rhythm Society 2017 guidelines, CS patients with a history of sustained VT, survivors of sudden cardiac arrest (SCA), $\mathrm{LVEF} \leq 35 \%$, and life expectancy of more than one year, placement of ICD is a class I indication [112]. In CS patients with an LVEF > 35\% with syncope, evidence of myocardial scar by MRI or PET, need for permanent pacing, and life expectancy of more than one year, implantation of ICD is reasonable (class IIa). In CS patients with an LVEF of greater than $35 \%$, if VA is inducible in an electrophysiologic study (EP), implantation of ICD is reasonable if life expectancy is more than one year (Class IIa). In addition, in CS patients who need permanent pacing, ICD implantation can be beneficial (Class IIa). If the CS patients have frequent symptomatic VAs and there is evidence of myocardial inflammation, immunosuppression and antiarrhythmic medications can be utilized to reduce the VA burden (Class IIa) [112]. In addition, based on our discussions until now, diagnosis of CS can be cumbersome and complicated due to its vague presentation and symptoms. Hence knowing how to utilize these diagnostic modalities becomes even more critical. In Figure 3, we propose our algorithm for evaluating patients who are suspicious for CS and incorporate their assessment for ICD implantation into a comprehensive algorithm.

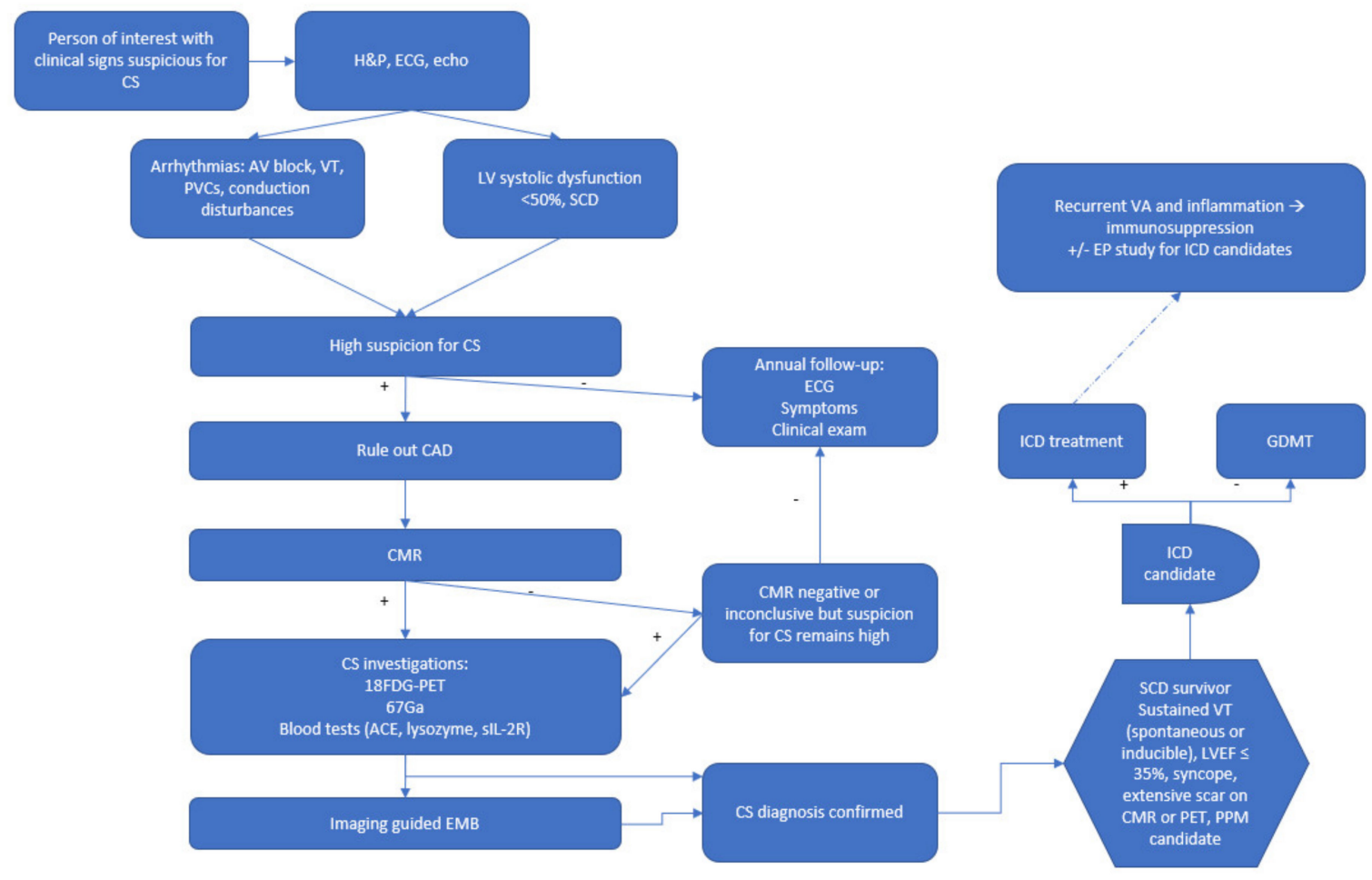

Figure 3. Cardiac Sarcoidosis (CS) diagnosis flowchart and implantable cardioverter-defibrillator (ICD) implantation timing. H\&P: history and physical. ECG: electrocardiogram. Echo: echocardiogram. AV: atrioventricular. PVC: premature ventricular contraction. LV: left ventricle. CAD: coronary artery disease. CMR: cardiac magnetic resonance imaging. EP: electrophysiology. Fluorodeoxyglucose (FDG) Positron Emission Tomography (PET). EMB: endomyocardial biopsy. 


\section{Conclusions}

It can be seen that CS is associated with a poor prognosis due to the high risk of sudden death, necessitating prompt diagnosis and treatment with anti-inflammatory medications in suspected individuals. Utilization of standard modalities such as ECG, Holter monitoring, and echocardiography in addition to a detailed medical history compromise the baseline for timely diagnosis of CS. After such clinical suspicion is raised, pursuing diagnosis with advanced modalities such as CMR and FDG-PET can be of great significance. Since timely diagnosis results in prompt treatment and an increased likelihood of good outcomes, we have proposed an algorithm that combines these different modalities in the diagnosis of CS.

Author Contributions: Conceptualization, I.P.-G.; writing-original draft preparation, all authors; writing-review and editing, I.P.-G., N.Y.; visualization, I.P.-G.; supervision, N.Y. All authors have read and agreed to the published version of the manuscript.

Funding: This research received no external funding.

Institutional Review Board Statement: Not applicable.

Informed Consent Statement: Not applicable.

Data Availability Statement: Not applicable.

Conflicts of Interest: The authors declare no conflict of interest.

\section{References}

1. Serei, V.D.; Fyfe, B. The many faces of cardiac sarcoidosis. Am. J. Clin. Pathol. 2020, 153, 294-302. [CrossRef] [PubMed]

2. Sharma, A.; Okada, D.R.; Yacoub, H.; Chrispin, J.; Bokhari, S. Diagnosis of cardiac sarcoidosis: An era of paradigm shift. Ann. Nucl. Med. 2020, 34, 87-93. [CrossRef]

3. Tan, J.L.; Fong, H.K.; Birati, E.Y.; Han, Y. Cardiac sarcoidosis. Am. J. Cardiol 2019, 123, 513-522. [CrossRef] [PubMed]

4. Markatis, E.; Afthinos, A.; Antonakis, E.; Papanikolaou, I.C. Cardiac sarcoidosis: Diagnosis and management. Rev. Cardiovasc. Med. 2020, 21, 321-338. [CrossRef] [PubMed]

5. Trivieri, M.G.; Spagnolo, P.; Birnie, D.; Liu, P.; Drake, W.; Kovacic, J.C.; Baughman, R.; Fayad, Z.A.; Judson, M.A. Challenges in cardiac and pulmonary sarcoidosis JACC state-of-the-art review. J. Am. Coll. Cardiol. 2020, 76, 1878-1901. [CrossRef]

6. Kusano, K.F.; Satomi, K. Diagnosis and treatment of cardiac sarcoidosis. Heart 2016, 102, 184-190. [CrossRef]

7. Mirsaeidi, M.; Machado, R.F.; Schraufnagel, D.; Sweiss, N.J.; Baughman, R.P. Racial difference in sarcoidosis mortality in the united states. Chest 2015, 147, 438-449. [CrossRef] [PubMed]

8. Martusewicz-Boros, M.M.; Boros, P.W.; Wiatr, E.; Zych, J.; Piotrowska-Kownacka, D.; Roszkowski-Sliz, K. Prevalence of cardiac sarcoidosis in white population: A case-control study Proposal for a novel risk index based on commonly available tests. Medicine 2016, 95, e4518. [CrossRef]

9. Birnie, D.H.; Nery, P.B.; Ha, A.C.; Beanlands, R.S.B. Cardiac sarcoidosis. J. Am. Coll. Cardiol. 2016, 68, 411-421. [CrossRef]

10. Locke, A.H.; Gurin, M.I.; Sabe, M.; Hauser, T.H.; Zimetbaum, P. Arrhythmia in cardiac sarcoidosis. Cardiol. Rev. J. 2020. publish ahead of print. [CrossRef]

11. Ipek, E.; Demirelli, S.; Ermis, E.; Inci, S. Sarcoidosis and the heart: A review of the literature. Intractable Rare Dis. Res. 2015, 4, 170-180. [CrossRef] [PubMed]

12. Keijsers, R.G.M.; Grutters, J.C. In which patients with sarcoidosis is FDG PET/CT indicated? J. Clin. Med. 2020, 9, 1-10. [CrossRef] [PubMed]

13. Roberts, W.C.; McAllister, H.A., Jr.; Ferrans, V.J. Sarcoidosis of the heart: A clinicopathologic study of 35 necropsy patients (group I) and review of 78 previously described necropsy patients (group II). Am. J. Med. 1977, 63, 86-108. [CrossRef]

14. Lagana, S.M.; Parwani, A.V.; Nichols, L.C. Cardiac sarcoidosis: A pathology-focused review. Arch. Pathol. Lab. Med. 2010, 134, 1039-1046. [CrossRef] [PubMed]

15. Roberts, W.C.; Chung, M.S.; Ko, J.M.; Capehart, J.E.; Hall, S.A. Morphologic features of cardiac sarcoidosis in native hearts of patients having cardiac transplantation. Am. J. Cardiol. 2014, 113, 706-712. [CrossRef]

16. Armstrong, D.; Gonzalez-Stawinski, G.V.; Ko, J.M.; Hall, S.A.; Roberts, W.C. The two extremes of cardiac sarcoidosis and the effect of prednisone therapy. Am. J. Cardiol. 2015, 115, 150-153. [CrossRef]

17. Matsui, Y.; Iwai, K.; Tachibana, T.; Fruie, T.; Shigematsu, N.; Izumi, T.; Homma, A.H.; Mikami, R.; Hongo, O.; Hiraga, Y. Clinicopathological study on fatal myocardial sarcoidosis. Ann. N. Y. Acad. Sci. 1976, 278, 455-469. [CrossRef]

18. Terasaki, F.; Kuwabara, H.; Takeda, Y.; Yamauchi, Y.; Fujita, S.; Nakamura, T.; Torii, I.; Hirose, Y.; Hoshiga, M. Clinical features and histopathology of cardiac sarcoidosis with refractory heart failure: An autopsy case. Intern. Med. 2020, 3551-3555. [CrossRef] 
19. Asimaki, A.; Tandri, H.; Duffy, E.R.; Winterfield, J.R.; Mackey-Bojack, S.; Picken, M.M.; Cooper, L.T.; Wilber, D.J.; Marcus, F.I.; Basso, C. Altered desmosomal proteins in granulomatous myocarditis and potential pathogenic links to arrhythmogenic right ventricular cardiomyopathy. Circ. Arrhythmia Electrophysiol. 2011, 4, 743-752. [CrossRef]

20. Lyle, M.A.; Cooper, L.T., Jr. Cardiovascular Outcomes in Sarcoidosis; American College of Cardiology Foundation: Washington, DC, USA, 2020.

21. Blankstein, R.; Stewart, G.C. Clinical Manifestation and Diagnosis of Cardiac Sarcoidosis. Available online: https://www. uptodate.com/contents/clinical-manifestations-and-diagnosis-of-cardiac-sarcoidosis (accessed on 1 April 2021).

22. Kandolin, R.; Lehtonen, J.; Airaksinen, J.; Vihinen, T.; Miettinen, H.; Ylitalo, K.; Kaikkonen, K.; Tuohinen, S.; Haataja, P.; Kerola, T.; et al. Cardiac sarcoidosis. Circulation 2015, 131, 624-632. [CrossRef]

23. Viles-Gonzalez, J.F.; Pastori, L.; Fischer, A.; Wisnivesky, J.P.; Goldman, M.G.; Mehta, D. Supraventricular arrhythmias in patients with cardiac sarcoidosis: Prevalence, predictors, and clinical implications. Chest 2013, 143, 1085-1090. [CrossRef] [PubMed]

24. Yigla, M.; Badarna-Abu-Ria, N.; Tov, N.; Ravell-Weiller, D.; Rubin, A. Sarcoidosis in northern Israel; clinical characteristics of 120 patients. SarcoidosisVasc. Diffus. Lung Dis. Off. J. Wasog 2002, 19, 220-226.

25. Ekström, K.; Lehtonen, J.; Nordenswan, H.-K.; Mäyränpää, M.I.; Räisänen-Sokolowski, A.; Kandolin, R.; Simonen, P.; Pietilä-Effati, P.; Alatalo, A.; Utriainen, S. Sudden death in cardiac sarcoidosis: An analysis of nationwi de clinical and cause-of-death registries. Eur. Heart J. 2019, 40, 3121-3128. [CrossRef] [PubMed]

26. Ward, E.V.; Nazari, J.; Edelman, R.R. Coronary artery vasculitis as a presentation of cardiac sarcoidosis. Circulation 2012, 125, e344-e346. [CrossRef]

27. Patel, A.R.; Patel, H. Cardiac Sarcoidosis: Remembering the Forgotten Right Ventricle; American College of Cardiology Foundation: Washington, DC, USA, 2020.

28. Patel, M.B.; Mor-Avi, V.; Murtagh, G.; Bonham, C.A.; Laffin, L.J.; Hogarth, D.K.; Medvedofsky, D.; Lang, R.M.; Patel, A.R. Right heart involvement in patients with sarcoidosis. Echocardiography 2016, 33, 734-741. [CrossRef] [PubMed]

29. Kagioka, Y.; Yasuda, M.; Okune, M.; Kakehi, K.; Kawamura, T.; Kobuke, K.; Miyazaki, S.; Iwanaga, Y. Right ventricular involvement is an important prognostic factor and risk stratification tool in suspected cardiac sarcoidosis: Analysis by cardiac magnetic resonance imaging. Clin. Res. Cardiol. 2020, 109, 988-998. [CrossRef]

30. Yafasova, A.; Fosbøl, E.L.; Schou, M.; Gustafsson, F.; Rossing, K.; Bundgaard, H.; Lauridsen, M.D.; Kristensen, S.L.; Torp-Pedersen, C.; Gislason, G.H. Long-term adverse cardiac outcomes in patients with sarcoidosis. J. Am. Coll. Cardiol. 2020, 76, 767-777. [CrossRef]

31. Birnie, D.H.; Sauer, W.H.; Bogun, F.; Cooper, J.M.; Culver, D.A.; Duvernoy, C.S.; Judson, M.A.; Kron, J.; Mehta, D.; Cosedis Nielsen, J.; et al. HRS expert consensus statement on the diagnosis and management of arrhythmias associated with cardiac sarcoidosis. Heart Rhythm. 2014, 11, 1305-1323. [CrossRef]

32. Terasaki, F.; Azuma, A.; Anzai, T.; Ishizaka, N.; Ishida, Y.; Isobe, M.; Inomata, T.; Ishibashi-Ueda, H.; Eishi, Y.; Kitakaze, M.; et al. JCS 2016 guideline on diagnosis and treatment of cardiac sarcoidosis—Digest Version. Circ. J. 2019, 83, 2329-2388. [CrossRef]

33. Terasaki, F.; Yoshinaga, K. New guidelines for diagnosis of cardiac sarcoidosis in Japan. Ann. Nucl. Cardiol. 2017, 3, 1-4. [CrossRef]

34. Judson, M.A.; Thompson, B.W.; Rabin, D.L.; Steimel, J.; Knattereud, G.L.; Lackland, D.T.; Rose, C.; Rand, C.S.; Baughman, R.P.; Teirstein, A.S. The diagnostic pathway to sarcoidosis*. CHEST 2003, 123, 406-412. [CrossRef] [PubMed]

35. Mantini, N.; Williams Jr., B.; Stewart, J.; Rubinsztain, L.; Kacharava, A. Cardiac Sarcoid: A Clinician's Review on How to Approach the Patient With Cardiac Sarcoid. Clin. Cardiol. 2012, 35, 410-415. [CrossRef]

36. Mayock, R.L.; Bertrand, P.; Morrison, C.E.; Scott, J.H. Manifestations of sarcoidosis: Analysis of 145 patients, with a review of nine series selected from the literature. Am. J. Med. 1963, 35, 67-89. [CrossRef]

37. Iannuzzi, M.C.; Fontana, J.R. Sarcoidosis: Clinical presentation, immunopathogenesis, and therapeutics. JAMA 2011, 305, 391-399. [CrossRef] [PubMed]

38. Ryland, K.L. Hepatic sarcoidosis: Incidence, monitoring, and treatment. Clin. Liver Dis. 2020, 16, 208-211. [CrossRef]

39. Yanardag, H.; Tetikkurt, C.; Bilir, M.; Demirci, S.; Iscimen, A. Diagnosis of cutaneous sarcoidosis; clinical and the prognostic significance of skin lesions. Multidiscip. Respir. Med. 2013, 8, 26. [CrossRef]

40. Obenauf, C.D.; Shaw, H.E.; Sydnor, C.F.; Klintworth, G.K. Sarcoidosis and its ophthalmic manifestations. Am. J. Ophthalmol. 1978, 86, 648-655. [CrossRef]

41. Mañá, J.; Gómez-Vaquero, C.; Montero, A.; Salazar, A.; Marcoval, J.; Valverde, J.; Manresa, F.; Pujol, R. Löfgren's syndrome revisited: A study of 186 patients. Am. J. Med. 1999, 107, 240-245. [CrossRef]

42. Takahashi, N.; Horie, T. Heerfordt syndrome. Nihon. Rinsho. 2002, 60, 1822-1826.

43. Banba, K.; Kusano, K.F.; Nakamura, K.; Morita, H.; Ogawa, A.; Ohtsuka, F.; Ogo, K.O.; Nishii, N.; Watanabe, A.; Nagase, S. Relationship between arrhythmogenesis and disease activity in cardiac sarcoidosis. Heart Rhythm. 2007, 4, 1292-1299. [CrossRef]

44. Epstein, A.E.; DiMarco, J.P.; Ellenbogen, K.A.; Estes, N.A., 3rd; Freedman, R.A.; Gettes, L.S.; Gillinov, A.M.; Gregoratos, G.; Hammill, S.C.; Hayes, D.L.; et al. ACC/AHA/HRS 2008 guidelines for device-based therapy of cardiac rhythm abnormalities: A report of the american college of cardiology/American heart association task force on practice guidelines (writing committee to revise the ACC/AHA/NASPE 2002 guideline update for implantation of cardiac pacemakers and antiarrhythmia devices) developed in collaboration with the American Association for thoracic surgery and society of thoracic surgeons. J. Am. Coll Cardiol. 2008, 51, e1-e62. [CrossRef] [PubMed] 
45. Kumar, S.; Barbhaiya, C.; Nagashima, K.; Choi, E.-K.; Epstein, L.M.; John, R.M.; Maytin, M.; Albert, C.M.; Miller, A.L.; Koplan, B.A.; et al. Ventricular tachycardia in cardiac sarcoidosis. Circ. Arrhythmia Electrophysiol. 2015, 8, 87-93. [CrossRef] [PubMed]

46. Homsi, M.; Alsayed, L.; Safadi, B.; Mahenthiran, J.; Das, M.K. Fragmented QRS complexes on 12-lead ECG: A marker of cardiac sarcoidosis as detected by gadolinium cardiac magnetic resonance imaging. Ann. Noninvasive Electrocardiol. 2009, 14, 319-326. [CrossRef] [PubMed]

47. Schuller, J.L.; Olson, M.D.; Zipse, M.M.; Schneider, P.M.; Aleong, R.G.; Wienberger, H.D.; Varosy, P.D.; Sauer, W.H. Electrocardiographic characteristics in patients with pulmonary sarcoidosis indicating cardiac involvement. J. Cardiovasc. Electrophysiol. 2011, 22, 1243-1248. [CrossRef]

48. Yazaki, Y.; Isobe, M.; Hiramitsu, S.; Morimoto, S.; Hiroe, M.; Omichi, C.; Nakano, T.; Saeki, M.; Izumi, T.; Sekiguchi, M. Comparison of clinical features and prognosis of cardiac sarcoidosis and idiopathic dilated cardiomyopathy. Am. J. Cardiol. 1998, 82, 537-540. [CrossRef]

49. Swanton, R.H. Sarcoidosis of the heart. Eur Heart J. 1988, 9 (Suppl. G), 169-174. [CrossRef]

50. Kraaijvanger, R.; Janssen Bonás, M.; Vorselaars, A.D.M.; Veltkamp, M. Biomarkers in the diagnosis and prognosis of sarcoidosis: Current use and future prospects. Front. Immunol. 2020, 11. [CrossRef]

51. Kolluri, N.; Rosenbaum, A.; Schmidt, T.; Kapa, S.; Blauwet, L. P1805Troponin-T, NT-proBNP and creatinine at presentation predict outcomes in patients with cardiac sarcoidosis. Eur. Heart J. 2019, 40. [CrossRef]

52. Iannuzzi, M.C.; Rybicki, B.A.; Teirstein, A.S. Sarcoidosis. N. Engl. J. Med. 2007, 357, 2153-2165. [CrossRef]

53. Kiko, T.; Yoshihisa, A.; Kanno, Y.; Yokokawa, T.; Abe, S.; Miyata-Tatsumi, M.; Misaka, T.; Oikawa, M.; Kobayashi, A.; Ishida, T. A multiple biomarker approach in patients with cardiac sarcoidosis. Int. Heart J. 2018, 59, 17-695. [CrossRef]

54. Mankad, P.; Mitchell, B.; Birnie, D.; Kron, J. Cardiac sarcoidosis. Curr. Cardiol. Rep. 2019, 21, 152. [CrossRef] [PubMed]

55. Bera, D.; Shanthi Naidu, K.; Kaur Saggu, D.; Yalagudri, S.; Kishor Kadel, J.; Sarkar, R.; Narasimhan, C. Serum angiotensin converting enzyme, Erythrocyte sedimentation rate and high sensitive-C reactive protein levels in diagnosis of cardiac sarcoidosiswhere do we stand? Indian Pacing Electrophysiol. J. 2020, 20, 184-188. [CrossRef] [PubMed]

56. Kandolin, R.; Lehtonen, J.; Airaksinen, J.; Vihinen, T.; Miettinen, H.; Kaikkonen, K.; Haataja, P.; Kerola, T.; Kupari, M. Usefulness of cardiac troponins as markers of early treatment response in cardiac sarcoidosis. Am. J. Cardiol. 2015, 116, 960-964. [CrossRef] [PubMed]

57. Baba, Y.; Kubo, T.; Kitaoka, H.; Okawa, M.; Yamanaka, S.; Kawada, Y.; Yamasaki, N.; Matsumura, Y.; Furuno, T.; Sugiura, T. Usefulness of high-sensitive cardiac troponin T for evaluating the activity of cardiac sarcoidosis. Int. Heart J. 2012, 53, 287-292. [CrossRef] [PubMed]

58. Kobayashi, S.; Myoren, T.; Oda, S.; Inari, M.; Ishiguchi, H.; Murakami, W.; Fukuda, M.; Tanaka, T.; Okuda, S.; Nao, T.; et al. Urinary 8-hydroxy-2'-deoxyguanosine as a novel biomarker of inflammatory activity in patients with cardiac sarcoidosis. Int. J. Cardiol. 2015, 190, 319-328. [CrossRef] [PubMed]

59. Fujiwara, W.; Kato, Y.; Hayashi, M.; Sugishita, Y.; Okumura, S.; Yoshinaga, M.; Ishiguro, T.; Yamada, R.; Ueda, S.; Harada, M. Serum microRNA-126 and-223 as new-generation biomarkers for sarcoidosis in patients with heart failure. J. Cardiol. 2018, 72, 452-457. [CrossRef]

60. Hulten, E.; Aslam, S.S.; Osborne, M.; Abbasi, S.; Biottencourt, M.S.; Blankstein, R. Cardiac sarcoidosis-state of the art review. Cardiovasc. Diagn. 2016, 6, 50-63.

61. Dubrey, S.W.; Sharma, R.; Underwood, R.; Mittal, T. Cardiac sarcoidosis: Diagnosis and management. Postgrad. Med. J. 2015, 91, 384-394. [CrossRef]

62. Sharma, O.P.; Maheshwari, A.; Thaker, K. Myocardial sarcoidosis. Chest 1993, 103, 253-258. [CrossRef]

63. Tellier, P.; Paycha, F.; Antony, I.; Nitenberg, A.; Valeyre, F.D.; Foult, J.-M.; Battesti, J.-P. Reversibility by dipyridamole of thallium-201 myocardial scan defects in patients with sarcoidosis. Am. J. Med. 1988, 85, 189-193. [CrossRef]

64. Fields, C.L.; Ossorio, M.A.; Roy, T.M.; Denny, D.M.; Varga, D.W. Thallium-201 scintigraphy in the diagnosis and management of myocardial sarcoidosis. South. Med. J. 1990, 83, 339-342. [CrossRef] [PubMed]

65. Kinney, E.L.; Caldwell, J.W. Do thallium myocardial perfusion scan abnormalities predict survival in sarcoid patients without cardiac symptoms? Angiology 1990, 41, 573-576. [CrossRef] [PubMed]

66. Keijsers, R.G.M.; van den Heuvel, D.A.F.; Grutters, J.C. Imaging the inflammatory activity of sarcoidosis. Eur. Respir. J. 2013, 41, 743-751. [CrossRef]

67. Akbar, J.J.; Meyer, C.A.; Shipley, R.T.; Vagal, A.S. Cardiopulmonary imaging in sarcoidosis. Clin. Chest Med. 2008, 29, 429-443. [CrossRef]

68. Futamatsu, H.; Suzuki, J.-i.; Adachi, S.; Okada, H.; Otomo, K.; Ohara, T.; Hashimoto, Y.; Kakuta, T.; Iesaka, Y.; Yamaguchi, H. Utility of gallium-67 scintigraphy for evaluation of cardiac sarcoidosis with ventricular tachycardia. Int. J. Cardiovasc. Imaging 2006, 22, 443-448. [CrossRef] [PubMed]

69. Nakazawa, A.; Ikeda, K.; Ito, Y.; Iwase, M.; Sato, K.; Ueda, R.; Dohi, Y. Usefulness of dual 67Ga and 99mTc-sestamibi singlephoton-emission CT scanning in the diagnosis of cardiac sarcoidosis. Chest 2004, 126, 1372-1376. [CrossRef] [PubMed]

70. Langah, R.; Spicer, K.; Gebregziabher, M.; Gordon, L. Effectiveness of prolonged fasting 18f-FDG PET-CT in the detection of cardiac sarcoidosis. J. Nucl. Cardiol. 2009, 16, 801-810. [CrossRef] [PubMed] 
71. Mehta, D.; Lubitz, S.A.; Frankel, Z.; Wisnivesky, J.P.; Einstein, A.J.; Goldman, M.; Machac, J.; Teirstein, A. Cardiac involvement in patients with sarcoidosis: Diagnostic and prognostic value of outpatient testing. Chest 2008, 133, 1426-1435. [CrossRef]

72. From, A.M.; Maleszewski, J.J.; Rihal, C.S. Current status of endomyocardial biopsy. Mayo Clin. Proc. 2011, 86, 1095-1102. [CrossRef]

73. Kim, J.S.; Judson, M.A.; Donnino, R.; Gold, M.; Cooper, L.T.; Prystowsky, E.N.; Prystowsky, S. Cardiac sarcoidosis. Am. Heart J. 2009, 157, 9-21. [CrossRef]

74. Uemura, A.; Morimoto, S.-i.; Hiramitsu, S.; Kato, Y.; Ito, T.; Hishida, H. Histologic diagnostic rate of cardiac sarcoidosis: Evaluation of endomyocardial biopsies. Am. Heart J. 1999, 138, 299-302. [CrossRef]

75. Ratner, S.J.; Fenoglio, J.J.; Ursell, P.C. Utility of endomyocardial biopsy in the diagnosis of cardiac sarcoidosis. Chest 1986, 90, 528-533. [CrossRef] [PubMed]

76. Nery, P.B.; Keren, A.; Healey, J.; Leug, E.; Beanlands, R.S.; Birnie, D.H. Isolated cardiac sarcoidosis: Establishing the diagnosis with electroanatomic mapping-guided endomyocardial biopsy. Can. J. Cardiol. 2013, 29, 1015.e1011-1015.e1013. [CrossRef] [PubMed]

77. Kandolin, R.; Lehtonen, J.; Graner, M.; Schildt, J.; Salmenkivi, K.; Kivistö, S.M.; Kupari, M. Diagnosing isolated cardiac sarcoidosis. J. Intern. Med. 2011, 270, 461-468. [CrossRef] [PubMed]

78. Cooper, L.T.; Baughman, K.L.; Feldman, A.M.; Frustaci, A.; Jessup, M.; Kuhl, U.; Levine, G.N.; Narula, J.; Starling, R.C.; Towbin, J.; et al. The role of endomyocardial biopsy in the management of cardiovascular disease: A scientific statement from the American heart association, the American college of cardiology, and the European society of cardiology endorsed by the heart failure society of America and the heart failure association of the european society of cardiology. J. Am. Coll. Cardiol. 2007, 50, 1914-1931. [CrossRef] [PubMed]

79. Ise, T.; Hasegawa, T.; Morita, Y.; Yamada, N.; Funada, A.; Takahama, H.; Amaki, M.; Kanzaki, H.; Okamura, H.; Kamakura, S.; et al. Extensive late gadolinium enhancement on cardiovascular magnetic resonance predicts adverse outcomes and lack of improvement in LV function after steroid therapy in cardiac sarcoidosis. Heart 2014, 100, 1165-1172. [CrossRef] [PubMed]

80. Ekstrom, K.; Lehtonen, J.; Hanninen, H.; Kandolin, R.; Kivisto, S.; Kupari, M. Magnetic resonance imaging as a predictor of survival free of life-threatening arrhythmias and transplantation in cardiac sarcoidosis. J. Am. Heart Assoc. 2016, 5, 1-9. [CrossRef] [PubMed]

81. Greulich, S.; Deluigi, C.C.; Gloekler, S.; Wahl, A.; Zurn, C.; Kramer, U.; Nothnagel, D.; Bultel, H.; Schumm, J.; Grun, S.; et al. CMR imaging predicts death and other adverse events in suspected cardiac sarcoidosis. JACCL Cardiovasc. Imaging 2013, 6, 501-511. [CrossRef]

82. Crouser, E.D.; Ono, C.; Tran, T.; He, X.; Raman, S.V. Improved Detection of cardiac sarcoidosis using magnetic resonance with myocardial T2 mapping. Am. J. Respir. Crit. Care Med. 2014, 189, 109-112.

83. Greulich, S.; Kitterer, D.; Latus, J.; Agour, E.; Steubing, H.; Kaesemann, P.; Patrascu, A.; Greiser, A.; Groeninger, S.; Mayr, A.; et al. Comprehensive cardiovascular magnetic resonance assessment in patients with sarcoidosis and preserved left ventricular ejection fraction. Circ. Cardiovasc. Imaging 2016, 9, e005022. [CrossRef]

84. Puntmann, V.O.; Isted, A.; Hinojar, R.; Foote, L.; Carr-White, G.; Nagel, E. T1 and T2 Mapping in recognition of early cardiac involvement in systemic sarcoidosis. Radiology 2017, 285, 63-72. [CrossRef]

85. Crouser, E.D.; Maier, L.A.; Wilson, K.C.; Bonham, C.A.; Morgenthau, A.S.; Patterson, K.C.; Abston, E.; Berstein, R.C.; Blankstein, R.; Chen, E.S.; et al. Diagnosis and detection of sarcoidosis an official American thoracic society clinical practice guideline. Am. J. Respir. Crit. Care Med. 2020, 201, e26-e51. [CrossRef]

86. Blankstein, R.; Kramer, C.M.; Chandrashekhar, Y. The challenges of diagnosing cardiac sarcoidosis. JACC Cardiovasc. Imaging 2017, 10, 1534-1536. [CrossRef] [PubMed]

87. Elwazir, M.Y.; Bois, J.P.; Ezzeddine, A.; Chareonthaitawee, P. Imaging and quantification of cardiac sarcoidosis. Semin. Nucl. Med. 2020, 50, 283-294. [CrossRef]

88. Chareonthaitawee, P.; Beanlands, R.S.; Chen, W.; Dorbala, S.; Miller, E.J.; Murthy, V.L.; Birnie, D.H.; Chen, E.S.; Cooper, L.T.; Tung, R.H.; et al. Joint SNMMI-ASNC expert consensus document on the role of 18F-FDG PET/CT in cardiac sarcoid detection and therapy monitoring. J. Nucl. Med. 2017, 58, 1341-1353. [CrossRef] [PubMed]

89. Youssef, G.; Leung, E.; Mylonas, I.; Williams, K.; Wisenberg, G.; Gulenchyn, K.Y.; de Kemp, R.A.; Da Silva, J.; Birnie, D.; Wells, G.A.; et al. The Use of 18F-FDG PET in the diagnosis of cardiac sarcoidosis: A systematic review and metaanalysis including the ontario experience. J. Nucl. Med. 2012, 53, 241-248. [CrossRef] [PubMed]

90. Blankstein, R.; Osborne, M.; Naya, M.; Waller, A.; Kim, C.K.; Murthy, V.L.; Kazemian, P.; Kwong, R.Y.; Tokuda, M.; Skali, H.; et al. Cardiac positron emission tomography enhances prognostic assessments of patients with suspected cardiac sarcoidosis. J. Am. Coll Cardiol. 2014, 63, 329-336. [CrossRef]

91. Sperry, B.W.; Tamarappoo, B.L.; Oldan, J.D.; Javed, O.; Culver, D.A.; Brunken, R.; Cerqueira, M.D.; Hachamovitch, R. Prognostic impact of extent, severity, and heterogeneity of abnormalities on 18F-FDG PET scans for suspected cardiac sarcoidosis. JACC Cardiovasc. Imaging 2018, 11, 336-345. [CrossRef]

92. Tuominen, H.; Haarala, A.; Tikkakoski, A.; Kahonen, M.; Nikus, K.; Sipila, K. FDG-PET in possible cardiac sarcoidosis: Right ventricular uptake and high total cardiac metabolic activity predict cardiovascular events. J. Nucl. Cardiol. 2021, 28, 199-205. [CrossRef]

93. Gotthardt, M.; Bleeker-Rovers, C.P.; Boerman, O.C.; Oyen, W.J.G. Imaging of inflammation by PET, conventional scintigraphy, and other imaging techniques. J. Nucl. Med. 2010, 51, 1937-1949. [CrossRef] [PubMed] 
94. Osborne, M.T.; Hulten, E.A.; Singh, A.; Waller, A.H.; Bittencourt, M.S.; Stewart, G.C.; Hainer, J.; Murthy, V.L.; Skali, H.; Dorbala, S.; et al. Reduction in 18F-fluorodeoxyglucose uptake on serial cardiac positron emission tomography is associated with improved left ventricular ejection fraction in patients with cardiac sarcoidosis. J. Nucl. Cardiol. 2014, 21, 166-174. [CrossRef] [PubMed]

95. Ambrosini, V.; Zompatori, M.; Fasano, L.; Nanni, C.; Nava, S.; Rubello, D.; Fanti, S. 18F-FDG PET/CT for the Assessment of Disease Extension and Activity in Patients With Sarcoidosis Results of a Preliminary Prospective Study. Clin. Nucl. Med. 2013, 38, e171-e177. [CrossRef] [PubMed]

96. Wicks, E.C.; Menezes, L.J.; Barnes, A.; Mohiddin, S.A.; Sekhri, N.; Porter, J.C.; Booth, H.L.; Garrett, E.; Patel, R.S.; Pavlou, M.; et al. Diagnostic accuracy and prognostic value of simultaneous hybrid 18F-fluorodeoxyglucose positron emission tomography/magnetic resonance imaging in cardiac sarcoidosis. Eur. Heart J. Cardiovasc. Imaging 2018, 19, 757-767. [CrossRef] [PubMed]

97. Vita, T.; Okada, D.R.; Veillet-Chowdhury, M.; Bravo, P.E.; Mullins, E.; Hulten, E.; Agrawal, M.; Madan, R.; Taqueti, V.R.; Steigner, M.; et al. Complementary value of cardiac magnetic resonance imaging and positron emission tomography/compute tomography in the assessment of cardiac sarcoidosis. Circ. Cardiovasc. Imaging 2018, 11, 1-11. [CrossRef] [PubMed]

98. Nappi, C.; El Fakhri, G. State of the art in cardiac hybrid technology: PET/MR. Curr. Cardiovasc. Imaging Rep. 2013, 6, 338-345. [CrossRef] [PubMed]

99. Robson, P.M.; Dey, D.; Newby, D.E.; Berman, D.; Li, D.; Fayad, Z.A.; Dweck, M.R. MR/PET imaging of the cardiovascular system. JACC Cardiovasc. Imaging 2017, 10, 1165-1179. [CrossRef]

100. Hamzeh, N.; Steckman, D.A.; Sauer, W.H.; Judson, M.A. Pathophysiology and clinical management of cardiac sarcoidosis. Nat. Rev. Cardiol. 2015, 12, 278-288. [CrossRef]

101. Sekhri, V.; Sanal, S.; Delorenzo, L.J.; Aronow, W.S.; Maguire, G.P. Cardiac sarcoidosis: A comprehensive review. Arch. Med. Sci. 2011, 7, 546-554. [CrossRef]

102. Birnie, D.; Beanlands, R.S.B.; Nery, P.; Aaron, S.D.; Culver, D.A.; DeKemp, R.A.; Gula, L.; Ha, A.; Healey, J.S.; Inoue, Y.; et al. Cardiac Sarcoidosis multi-center randomized controlled trial (CHASM CS- RCT). Am. Heart J. 2020, 220, 246-252. [CrossRef]

103. Sadek, M.M.; Yung, D.; Birnie, D.H.; Beanlands, R.S.; Nery, P.B. Corticosteroid therapy for cardiac sarcoidosis: A systematic review. Can. J. Cardiol. 2013, 29, 1034-1041. [CrossRef]

104. Yazaki, Y.; Isobe, M.; Hiroe, M.; Morimoto, S.-I.; Hiramitsu, S.; Nakano, T.; Izumi, T.; Sekiguchi, M. Prognostic determinants of long-term survival in Japanese patients with cardiac sarcoidosis treated with prednisone. Am. J. Cardiol. 2001, 88, 1006-1010. [CrossRef]

105. Harper, L.J.; McCarthy, M.; Ribeiro Neto, M.L.; Hachamovitch, R.; Pearson, K.; Bonanno, B.; Shaia, J.; Brunken, R.; Joyce, E.; Culver, D.A. Infliximab for refractory cardiac sarcoidosis. Am. J. Cardiol. 2019, 124, 1630-1635. [CrossRef] [PubMed]

106. Koplan, B.A.; Soejima, K.; Baughman, K.; Epstein, L.M.; Stevenson, W.G. Refractory ventricular tachycardia secondary to cardiac sarcoid: Electrophysiologic characteristics, mapping, and ablation. Heart Rhythm. 2006, 3, 924-929. [CrossRef] [PubMed]

107. Stees, C.S.; Khoo, M.S.; Lowery, C.M.; Sauer, W.H. Ventricular tachycardia storm successfully treated with immunosuppression and catheter ablation in a patient with cardiac sarcoidosis. J. Cardiovasc. Electrophysiol. 2011, 22, 210-213. [CrossRef] [PubMed]

108. Yodogawa, K.; Seino, Y.; Ohara, T.; Takayama, H.; Katoh, T.; Mizuno, K. Effect of corticosteroid therapy on ventricular arrhythmias in patients with cardiac sarcoidosis. Ann. Noninvasive Electrocardiol. 2011, 16, 140-147. [CrossRef] [PubMed]

109. Segawa, M.; Fukuda, K.; Nakano, M.; Kondo, M.; Satake, H.; Hirano, M.; Shimokawa, H. Time course and factors correlating with ventricular tachyarrhythmias after introduction of steroid therapy in cardiac sarcoidosis. Circ. Arrhythm. Electrophysiol. 2016, 9. [CrossRef]

110. Echt, D.S.; Liebson, P.R.; Mitchell, L.B.; Peters, R.W.; Obias-Manno, D.; Barker, A.H.; Arensberg, D.; Baker, A.; Friedman, L.; Greene, H.L.; et al. Mortality and morbidity in patients receiving encainide, flecainide, or placebo. The cardiac arrhythmia suppression trial. N. Engl. J. Med. 1991, 324, 781-788. [CrossRef]

111. Yada, H.; Soejima, K. Management of arrhythmias associated with cardiac sarcoidosis. Korean Circ. J. 2019, 49, 119-133. [CrossRef]

112. Al-Khatib, S.M.; Stevenson, W.G.; Ackerman, M.J.; Bryant, W.J.; Callans, D.J.; Curtis, A.B.; Deal, B.J.; Dickfeld, T.; Field, M.E.; Fonarow, G.C.; et al. 2017 AHA/ACC/HRS guideline for management of patients with ventricular arrhythmias and the prevention of sudden cardiac death. JACC 2018, 72, e91-e220. [CrossRef] 